\title{
Effect of target density uncertainties on extracted experimental cross sections for the ${ }^{\text {nat }} \mathrm{Ti}(\alpha, x)^{51} \mathrm{Cr},{ }^{46} \mathrm{Sc}$ reactions
}

\author{
Ahmed Rufai Usman ${ }^{1, *}$, Mayeen Uddin Khandaker $^{2, *}$ and Hiromitsu $\mathrm{Haba}^{3}$ \\ ${ }^{1}$ Department of Physics, Umaru Musa Yar'adua University, Katsina, Nigeria \\ ${ }^{2}$ Center for Biomedical Physics, School of Healthcare and Medical Sciences, Sunway University, 47500 Bandar Sunway, Malaysia \\ ${ }^{3}$ Nishina Center for Accelerator-Based Science, RIKEN, Wako, Saitama 351-0198, Japan
}

\begin{abstract}
The production optimization of medical radioisotopes for various applications requires careful analysis of all production parameters. The importance of such radioisotopes in nuclear medicine cannot be overemphasized. During cross section calculations, experimentalist sometimes find more than one reported literature value of a certain parameter, each leading to a different effect on the overall cross sections. In the present work, we considered the effect of slight variations of density values of titanium reported in the literature on the experimental cross sections. Several reported density values $\left(4.50,4.51\right.$ and $\left.4.54 \mathrm{~g} / \mathrm{cm}^{3}\right)$ were found in the literature, but only the lowest and highest values $\left(4.50\right.$ and $\left.4.54 \mathrm{~g} / \mathrm{cm}^{3}\right)$ were considered in this study. The said densities were used to calculate the cross sections of $\operatorname{Ti}(\alpha, \mathrm{x}){ }^{51} \mathrm{Cr},{ }^{46} \mathrm{Sc}$ radioisotopes. The corresponding trends of the excitation functions of ${ }^{51} \mathrm{Cr}$ and ${ }^{46} \mathrm{Sc}$ were analyzed for the selected density values. The calculated cross sections from the different density values have been analyzed and compared graphically to show the level of variations, as well as comparison with theoretical TALYS code calculated cross sections. About 1 percent variation of the cross sections have been observed. Following the observed slight variation in cross sections effect of the various density values, we recommend that IAEA could update its nuclear data service database to include recommended density values for all metals using reliable sources.
\end{abstract}

\section{Introduction}

Production cross sections of radioisotopes are important for their applications in nuclear medicine, astrophysical studies and many other fields. From the popular cross section equation Eq. (1) [1], several parameters and quantities such as the beam intensity, atomic density, target thickness, atomic decay data, etc. are involved during calculation of the cross sections. Small variation of one quantity or parameter could lead to an effect on the overall cross sections. As an example, a slight difference in the values of decay characteristics of one radioisotope may give an obvious difference of final cross section values.

Density is one of the important parameters useful in the calculation of cross sections. However, following the availability of many works in the literature, researchers sometimes find several values of the atomic densities on same element. Each of these values when used in Eq. (1), would give a particular value of cross sections. A simple online search of density of titanium will yield several literature values such as $4.5 \mathrm{~g} / \mathrm{cm}^{3}[2], 4.51 \mathrm{~g} / \mathrm{cm}^{3}[3,4]$ and $4.54 \mathrm{~g} / \mathrm{cm}^{3}$ [5].

The aim of the present work is to have a closer look on the effect of atomic density on the overall cross section calculations of ${ }^{46} \mathrm{Sc}$ and ${ }^{51} \mathrm{Cr}$ via ${ }^{\text {nat }} \mathrm{Ti}(\alpha, x){ }^{51} \mathrm{Cr}$ and ${ }^{\text {nat }} \mathrm{Ti}(\alpha, x){ }^{51} \mathrm{Cr}$ reactions respectively. Both ${ }^{46} \mathrm{Sc}$ and ${ }^{51} \mathrm{Cr}$ are very important radioisotopes with several applications.
Following the good decay characteristics of ${ }^{46} \mathrm{Sc}\left(T_{1 / 2}\right.$ $=83.79 \mathrm{~d}$, decay modes: $\beta^{-}(100 \%) ; 889 \mathrm{keV}\left(I_{\gamma}=99.98\right)$, $\left.1120.545 \mathrm{keV}\left(I_{\gamma}=99.99\right)\right)$, the radioisotope has been proposed as ideal in beam monitoring, just as the popularly known ${ }^{48} \mathrm{~V}$ radioisotope [6]. Similarly, the excellent decay characteristics of ${ }^{51} \mathrm{Cr}$ and its fine shape of excitation function which make it useful in monitoring irradiations under alpha beams [7]. The ${ }^{51} \mathrm{Cr}$ is also used to label red blood cells for measurements of mass or volume of blood $[8,9]$ and in labeling platelets to determine their survival period as well as in diagnosis of gastrointestinal bleeding through sequestration studies [9].

\section{Experimental}

The detailed experimental procedure is available in our previous studies $[1,10]$. The stacked-foils activation technique was employed for the irradiation of target while an offline HPGe $\gamma$-ray spectrometry was used to measure the emitted gamma activities from the irradiated foils. Titanium foil $10.40 \mu \mathrm{m}$ thick (source: Goodfellow company, UK, purity: $>99.6 \%$ ) of isotopic natural composition $\left({ }^{46} \mathrm{Ti}: 8.25 \%\right.$; ${ }^{47} \mathrm{Ti}: 7.44 \%$; ${ }^{48} \mathrm{Ti}: 73.72 \%$; ${ }^{49} \mathrm{Ti}: 5.41 \%$; ${ }^{50} \mathrm{Ti}: 5.18 \%$ [11] was used as a target material in a stack also consisting of foils of copper and holmium. A target holder in the form of Faraday-liked cup was made to hold the prepared stack for the irradiation by

\footnotetext{
* Corresponding author: amadirufai@yahoo.com (A.R. Usman); mu_khandaker@yahoo.com (M.U. Khandaker)
} 
alpha beam. The irradiation was done using the AVF cyclotron of RI Beam Factory, Nishina Centre for accelerator-based science, RIKEN Institute, Japan.

The irradiated foils were transferred from the from irradiation room to a hot laboratory where a gamma ray spectrometer was used for measurements of gamma activities using a high-resolution $\mathrm{HP}$ Ge $\gamma$-ray spectrometer. The spectrometer was coupled to a 4096 multi-channel analyser as well as some other associated electronics. Analysis of the gamma spectra was performed using a gamma program, a Maestro software (ORTEC; Ver. 7.01).

The incident beam intensity on our stack was calculated using gamma activities from a Ti foil placed at the front position of the irradiated stack, making the foil to receive a $50 \mathrm{MeV}$ alpha beam delivered by the cyclotron. The beam intensity of the alpha beam was determined using the IAEA recommended nat $\mathrm{Ti}(\alpha, x)^{51} \mathrm{Cr}$ monitor reaction $\left(\sigma=26.4 \mathrm{mb}\right.$ at $\left.E_{\alpha}=50 \mathrm{MeV}\right)$ [12]. The calculated intensity of the alpha beam was considered constant throughout the stack and was thus used for the calculation of cross-sections of each stacked foil. The alpha beam energy on each foil in the stack was calculated using a computer software, SRIM-2003 [13].

The cross-sections, $\sigma(\mathrm{E})$, of the studied radioisotopes were extracted from experimental data using the activation formula used in our previous studies [14-18] by taking into account some target parameters such as thickness and density, as well as the parameters of the incident bombarding particles. The calculations of the cross sections were done twice using two literature titanium density sources: 1) $4.50 \mathrm{~g} / \mathrm{cm}^{3}$. 2) $4.54 \mathrm{~g} / \mathrm{cm}^{3}$.

$$
\begin{aligned}
& \sigma\left(E_{i}\right) \\
& =\frac{C\left(E_{j}\right) \lambda}{\varepsilon_{\gamma} I_{\gamma} t_{\mathrm{h}} \rho \varphi\left(1-e^{-\lambda t_{i r r}}\right)\left(e^{-\lambda t_{c o o}}\right)\left(1-e^{-\lambda t_{m e a}}\right)},
\end{aligned}
$$

In which $C\left(E_{\mathrm{j}}\right)$ stands for the net counts of the nuclide under the photo-peak area at the $j$-th sample, $\lambda$ represents the decay constant $\left(\lambda=[\ln 2] / T_{\frac{1}{2}}\right)$ of the radioisotope, $\varepsilon_{\gamma}$ is for efficiency of detection, $t_{\mathrm{h}}$ is the thickness $(\mathrm{cm})$ of the irradiated foil while $\rho$ is the atomic density of the target $\left(8.49 \times 10^{22}\right.$ atoms $\left./ \mathrm{cm}^{3}\right)$. Similarly, $\varphi$ is the intensity of the alpha beam $\left(5.45 \times 10^{11}\right.$ particle/s $)$, while $t_{i r r}, t_{c o o}$ and $t_{m e a}$ respectively are for irradiation, cooling and measurement time.

The decay data of the ${ }^{46} \mathrm{Sc}$ and ${ }^{51} \mathrm{Cr}$ were adopted from the ENSDF library $[19,20]$ and retrieved from the interface of Live Chart of nuclides [21]. The Q-values presented in Table 2 were calculated based on the AME mass evaluation [22] and were extracted via the Q-tool system [23].

\section{Results and Discussion}

The measured production cross-sections of ${ }^{46} \mathrm{Sc}$ and ${ }^{51} \mathrm{Cr}$ radioisotopes using two different literature density values are tabulated in Tables 2 and 3 respectively. The excitation functions are shown in Figs. 1 and 2 together with the evaluated data from the TENDL-2014 library [24].

The ${ }^{46} \mathrm{Sc}$ was identified and analysed through the gamma activities of its intense and interference free gamma line, $E_{\gamma}=889.277 \mathrm{keV}\left(I_{\gamma}=99.9840 \%\right)$. The ${ }^{46 \mathrm{~g}} \mathrm{Sc}$ decays to stable ${ }^{46} \mathrm{Ti}$ via $\beta^{-}$decay $(100 \%)$. The crosssection of this radioisotope is cumulative, as it has two states $\left({ }^{46 \mathrm{~g}} \mathrm{Sc}\right.$ and $\left.{ }^{46 \mathrm{~m}} \mathrm{Sc}\right)$. The isomeric state $\left({ }^{46 \mathrm{~m}} \mathrm{Sc}\right)$ has very short half-life $\left(T_{1 / 2}=18.75 \mathrm{~s}\right)$, and could not be measured in the present experimental conditions, eventually decayed within 5 mins of EOB (end of bombardment) to ${ }^{46 \mathrm{~g}} \mathrm{Sc}\left(T_{1 / 2}=83.79 \mathrm{~d}\right)$ via IT $(100 \%)$ process. In Table 2 , the measured cross-sections for ${ }^{46} \mathrm{Sc}$ for the two used densities have been presented, whereas Fig. 1 compares the measured excitation functions with the theoretical calculation from the Talys nuclear reaction code via the TENDL-2014 library. The extracted data of TENDL-2014 indicate lower values relative to the present measurement.

TABLE 1: Decay data of the radioisotopes adopted in this study as evaluated decay data in the ENSDF library [19, 20] extracted from the interface of Live Chart of nuclides [21] while Q-values [22] were extracted from Qtool system [23].

\begin{tabular}{|c|c|c|c|c|}
\hline Nuclide & Half-life & 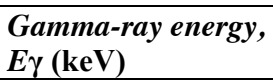 & $\begin{array}{l}\text { Branching ratio, } \\
\text { I } \gamma(\%)\end{array}$ & Contributing reactions \\
\hline \multirow[t]{4}{*}{${ }^{46 g} \mathrm{Sc}$} & $83.79 \mathrm{~d}$ & 889.28 & 99.98 & ${ }^{47} \mathrm{Ti}(\alpha, \mathrm{p} \alpha){ }^{46} \mathrm{Sc}$ \\
\hline & & 1120.55 & 99.99 & ${ }^{48} \mathrm{Ti}(\alpha, \mathrm{d} \alpha)^{46} \mathrm{Sc}$ \\
\hline & & & & ${ }^{49} \operatorname{Ti}(\alpha, \mathrm{nd} \alpha)^{46} \mathrm{Sc}$ \\
\hline & & & & ${ }^{50} \mathrm{Ti}(\alpha, \mathrm{d} \alpha 2 \mathrm{n}){ }^{46} \mathrm{Sc}$ \\
\hline \multirow[t]{5}{*}{${ }^{51} \mathrm{Cr}$} & $27.7025 \mathrm{~d}$ & 320.0824 & 9.910 & $\left.{ }^{47} \mathrm{Ti}(\alpha, \gamma)\right)^{51} \mathrm{Cr}$ \\
\hline & & & & ${ }^{48} \mathrm{Ti}(\alpha, \mathrm{n}){ }^{51} \mathrm{Cr}$ \\
\hline & & & & ${ }^{49} \mathrm{Ti}(\alpha, 2 \mathrm{n}){ }^{51} \mathrm{Cr}$ \\
\hline & & & & ${ }^{50} \mathrm{Ti}(\alpha, 3 \mathrm{n}){ }^{51} \mathrm{Cr}$ \\
\hline & & & & $\mathrm{EC}$ and $\beta^{+}(100 \%)$ decay of ${ }^{51} \mathrm{Mn}$ \\
\hline
\end{tabular}


Table 2. Measured cross-sections for ${ }^{\mathrm{nat}} \mathrm{Ti}(\alpha, \mathrm{x})^{46} \mathrm{Sc}$ nuclear processes.

\begin{tabular}{|c|c|c|c|c|}
\hline \multirow{2}{*}{$\begin{array}{l}\text { Energy } \\
(\mathrm{MeV})\end{array}$} & \multicolumn{2}{|c|}{ Cross-sections (mb) } & \multirow{2}{*}{$\begin{array}{l}\text { Cross } \\
\text { section } \\
\text { difference } \\
(\mathbf{m b})\end{array}$} & \multirow{2}{*}{$\begin{array}{l}\text { Difference } \\
(\%)\end{array}$} \\
\hline & $\begin{array}{c}\rho=4.54 \\
\mathrm{~g} / \mathrm{cm}^{3}\end{array}$ & $\begin{array}{c}\rho=4.50 \\
\mathrm{~g} / \mathrm{cm}^{3}\end{array}$ & & \\
\hline 50.2 & 76.089 & 76.765 & 0.676 & 0.881 \\
\hline 47.4 & 69.731 & 70.351 & 0.620 & 0.881 \\
\hline 42.9 & 42.423 & 42.800 & 0.377 & 0.881 \\
\hline 38.1 & 16.332 & 16.477 & 0.145 & 0.881 \\
\hline 32.8 & 4.429 & 4.468 & 0.039 & 0.881 \\
\hline 26.8 & 2.103 & 2.121 & 0.019 & 0.881 \\
\hline
\end{tabular}

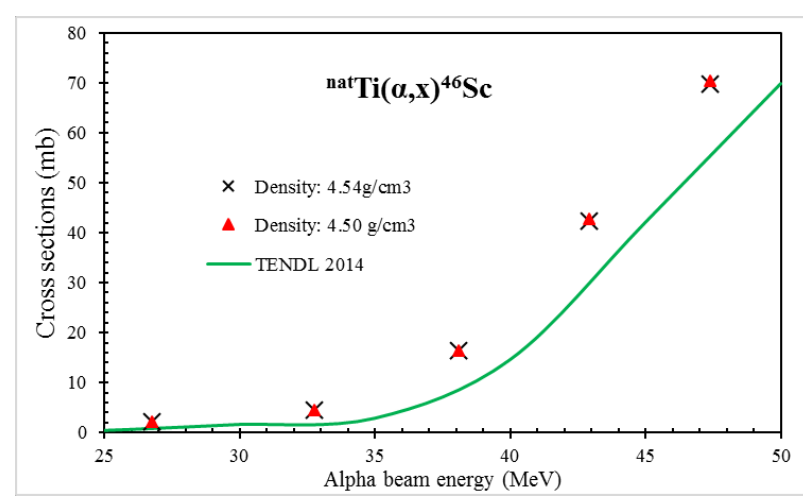

Fig. 1. Excitation function for ${ }^{\text {nat }} \mathrm{Ti}(\alpha, \mathrm{x})^{46} \mathrm{Sc}$ reaction

The extracted cross sections for ${ }^{51} \mathrm{Cr}\left(T_{1 / 2}=27.7025 \mathrm{~d}\right)$ were shown in Table 3 using the two density values indicated in the table. The ${ }^{51} \mathrm{Cr}$ decays through EC (100\%) decay to ${ }^{51} \mathrm{~V}$. Measurement of this radioisotope was performed via its relatively intense gamma line, $E_{\gamma}=$ $320.0824 \mathrm{keV}\left(I_{\gamma}=9.910 \%\right)$. The excitation functions of the ${ }^{51} \mathrm{Cr}$ for the two considered densities are shown in Fig 2 together with extracted TENDL-2014. The TENDL2014 underestimates the measured cross-sections as presented in Fig. 2.

Table 3. Measured cross-sections for ${ }^{\text {nat }} \mathrm{Ti}(\alpha, \mathrm{x})^{51} \mathrm{Cr}$ nuclear processes.

\begin{tabular}{|c|c|c|c|c|}
\hline \multirow{2}{*}{$\begin{array}{l}\text { Energy } \\
(\mathrm{MeV})\end{array}$} & \multicolumn{2}{|c|}{ Cross-sections (mb) } & \multirow{2}{*}{$\begin{array}{l}\text { Cross } \\
\text { section } \\
\text { difference } \\
(\mathrm{mb}) \\
\end{array}$} & \multirow{2}{*}{$\begin{array}{l}\text { Difference } \\
(\%)\end{array}$} \\
\hline & $\begin{array}{c}\rho=4.54 \\
\mathrm{~g} / \mathrm{cm}^{3}\end{array}$ & $\begin{array}{c}\rho=4.50 \\
\mathrm{~g} / \mathrm{cm}^{3}\end{array}$ & & \\
\hline 50.2 & 26.137 & 26.369 & 0.232 & 0.881 \\
\hline 47.4 & 34.339 & 34.644 & 0.305 & 0.881 \\
\hline 42.9 & 35.844 & 36.163 & 0.319 & 0.881 \\
\hline 38.1 & 46.428 & 46.840 & 0.413 & 0.881 \\
\hline 32.8 & 61.753 & 62.302 & 0.549 & 0.881 \\
\hline 26.8 & 72.849 & 73.497 & 0.648 & 0.881 \\
\hline 19.7 & 209.406 & 211.267 & 1.861 & 0.881 \\
\hline 10.4 & 412.603 & 416.270 & 3.668 & 0.881 \\
\hline
\end{tabular}

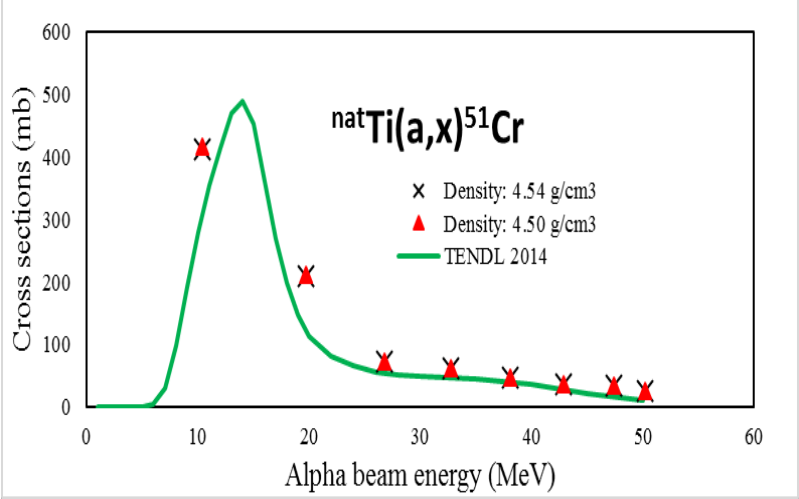

Fig. 2. Excitation function of ${ }^{\text {nat }} \mathrm{Ti}(\alpha, \mathrm{x})^{51} \mathrm{Cr}$ reaction

\section{Conclusion}

The experimental cross-sections of ${ }^{46} \mathrm{Sc}$ and ${ }^{51} \mathrm{Cr}$ radioisotopes have been obtained from experimental data assuming two different density values (4.50 and 4.54 $\mathrm{g} / \mathrm{cm}^{3}$ ). The calculations indicate a slight variation of the overall cross sections relative to the slight density differences. An average of one (1) percent variation was observed in both production cross section. The variation could be much higher in other metals were the reported density literature data is much wider than in titanium.

As a very active monitoring body, the IAEA is recommended to update their database with density values of all metals using the most reliable literature sources. This will help to minimize the slight variations observed by different researchers based on density difference and in turn will lead to better optimization.

This work was carried out at RI Beam Factory operated by RIKEN Nishina Center and CNS, University of Tokyo Japan.

\section{References}

1. A.R. Usman, M.U. Khandaker, H. Haba, N. Otuka, M. Murakami, Excitation functions of alpha particles induced nuclear reactions on natural titanium in the energy range of $10.4-$ 50.2 MeV., Nuclear Instruments and Methods in Physics Research Section B: Beam Interactions with Materials and Atoms, 399 (2017) 34-47.

2. CEFA, 2016. Chemical element, titanium. Chemistry explained, foundations and applications. Accessed 21/03/2019 from: http://www.chemistryexplained.com/elements/T -Z/Titanium.html

3. W.D. Callister and D.G. Rethwisch, 2010. Materials Science and Engineering: An Introduction, 8th Edition 8th Edition. John Wiley and Sons., Inc. 2010

4. RSC, 2019. Periodic table, titanium. Royal Society of Chemistry 2019. Access on 23/03/2019 from http://www.rsc.org/periodictable/element/22/titanium

5. Y. Bentor, 2012. Chemical Element.com Titanium. Accessed Sep. 2, 2019 from 
http://www.chemicalelements.com/elements/ti. html

6. A. Hermanne, F. Tárkányi, S. Takács, F. Ditrói, N. Amjed, Excitation functions for production of 46Sc by deuteron and proton beams in ${ }^{\text {nat }} \mathrm{Ti}: \mathrm{A}$ basis for additional monitor reactions, Nuclear Instruments and Methods in Physics Research Section B: Beam Interactions with Materials and Atoms, 338 (2014) 31-41.

7. IAEA, Charged particle reference cross sections, Monitor reactions, International Atomic Anergy. Available at https:/wwwnds.iaea.org/medical/monitor_reactions.html, (2007).

8. M. Al-Abyad, I. Spahn, S.M. Qaim, Experimental studies and nuclear model calculations on proton induced reactions on manganese up to $45 \mathrm{MeV}$ with reference to production of ${ }^{55} \mathrm{Fe},{ }^{54} \mathrm{Mn}$ and ${ }^{51} \mathrm{Cr}$, Applied Radiation and Isotopes, 68 (2010) 2393-2397.

9. K.V. Vimalnath, A. Rajeswari, S. Chakraborty, A. Dash, Large scale production of $51 \mathrm{Cr}$ for medical application in a medium flux research reactor: A comparative investigation of SzilardChalmers process and direct $(n, \gamma)$ route, Applied Radiation and Isotopes, 91 (2014) 104-108.

10. A.R. Usman, M.U. Khandaker, H. Haba, Cyclotron production of ${ }^{48} \mathrm{~V}$ via ${ }^{\text {nat }} \mathrm{Ti}(\mathrm{d}, \mathrm{x})^{48} \mathrm{~V}$ nuclear reaction; a promising radionuclide, Journal of Physics: Conference Series, 860 (2017) 012029.

11. M. Berglund, M.E. Wieser, Isotopic compositions of the elements 2009 (IUPAC Technical Report), Pure and Applied Chemistry, 83 (2011) 397-410.

12. S.M. Qaim, F.T. Tárkányi, P. Obložinský, K. Gul, A. Hermanne, M. Mustafa, F. Nortier, B. Scholten, Y.N. Shubin, S. Takács, Chargedparticle cross section database for medical radioisotope production, Journal of Nuclear Science and Technology, 39 (2002) 1282-1285.

13. J.F. Ziegler, SRIM-2003, Nuclear Instruments and Methods in Physics Research Section B: Beam Interactions with Materials and Atoms, 219-220 (2004) 1027-1036.

14. M.U. Khandaker, H. Haba, N. Otuka, A.R. Usman, Investigation of $(\mathrm{d}, \mathrm{x})$ nuclear reactions on natural ytterbium up to $24 \mathrm{MeV}$, Nuclear Instruments and Methods in Physics Research Section B: Beam Interactions with Materials and Atoms, 335 (2014) 8-18.

15. A.R. Usman, M.U. Khandaker, H. Haba, N. Otuka, Material science as basis for nuclear medicine: Holmium irradiation for radioisotopes production, AIP Conference Proceedings, AIP Publishing, 2018, pp. 020020.

16. A.R. Usman, M.U. Khandaker, H. Haba, N. Otuka, M. Murakami, Y. Komori, Production cross-sections of radionuclides from $\alpha$-induced reactions on natural copper up to $50 \mathrm{MeV}$, Applied Radiation and Isotopes, 114 (2016) 104113.

17. A.R. Usman, M.U. Khandaker, H. Haba, M. Murakami, N. Otuka, Measurements of deuteron-induced reaction cross-sections on natural nickel up to $24 \mathrm{MeV}$, Nuclear Instruments and Methods in Physics Research Section B: Beam Interactions with Materials and Atoms, 368 (2016) 112-119.

18. M.U. Khandaker, H. Haba, M. Murakami, N. Otuka, H.A. Kassim, Excitation functions of deuteron-induced nuclear reactions on natural platinum up to $24 \mathrm{MeV}$, Nuclear Instruments and Methods in Physics Research Section B: Beam Interactions with Materials and Atoms, 362 (2015) 151-162.

19. S.C. Wu, Nuclear Data Sheets for $\mathrm{A}=46$, Nuclear Data Sheets, 91 (2000) 1-116.

20. H. Xiaolong, Nuclear Data Sheets for $A=51$, Nuclear Data Sheets, 107 (2006) 2131-2322.

21. IAEA, LiveChart of Nuclides, Interractive Chart of Nuclides, International Atomic Anergy. Available at https://wwwnds.iaea.org/medical/monitor_reactions.html, (2009).

22. G. Audi, A.H. Wapstra, C. Thibault, The AME2003 atomic mass evaluation: (II). Tables, graphs and references, Nuclear Physics A, 729 (2003) 337-676.

23. Qtool, Calculation of Reaction Q-values and thresholds, US Department of Energy, USA, Los Alamos National Laboratory, 2011.

24. A.J. Koning, D. Rochman, S.C van der Marck, J. Kopecky, J.C. Sublet, S. Pomp, H. Sjostrand, R. Forrest, E. Bauge, S. Hilaire, TENDL-2014: TALYS-based evaluated nuclear data library, Nuclear Research and Consultancy Group (NRG) Petten, The Netherlands, Netherlands, 2014. 